\title{
LETTER
}

\section{The relationship between arterial transducer level and pulse contour waveform-derived measurements}

\author{
Huaiwu He, Dawei Liu*, Yun Long, Xiaoting Wang, Yuan Yu, Xin Li, Hailing Guo, Jing Cai and Ning Fang
}

For hemodynamic monitoring, the pressure transducer is suggested to be fixed at the level of the phlebostatic axis in critically ill patients [1,2]. The correction and adjustment of pressure transducer are emphasized in central venous pressure monitoring in clinical practice. The exact position of the transducer is relatively easy to be ignored for invasive arterial blood pressure monitoring $[3,4]$. Improper position of the transducer may cause inaccurate value and shape of the arterial blood pressure wave, which would result in an invalid PiCCO (Pulsion Medical Systems AG, Munich, Germany) algorithm for pulse contour waveform-derived measurements. This study was conducted as a prospective quantitative evaluation of the relationship between arterial transducer level and pulse contour waveform-derived measurements.

In total, 22 patients were enrolled in the 28-bed department of critical care medicine of a university hospital. All of the patients had a femoral artery catheter for PiCCO hemodynamic monitoring. The site of the phlebostatic axis was defined as the zero level (reference level). We moved the arterial pressure transducer up and down at eight different levels $(-5 \mathrm{~cm},-10 \mathrm{~cm}$, $-15 \mathrm{~cm},-20 \mathrm{~cm}, 5 \mathrm{~cm}, 10 \mathrm{~cm}, 15 \mathrm{~cm}, 20 \mathrm{~cm})$. At each level, continuous cardiac index (CCI), rate of left ventricular pressure rise during systole ( $\mathrm{dP} / \mathrm{dtmax})$, and systemic vascular resistance index (SVRI) were simultaneously recorded.

The elevation of pressure transducer caused significantly positive changes in $\mathrm{CCI}$ and negative changes in
$\mathrm{dP} / \mathrm{dtmax}$ and SVRI, which resulted in a change in the opposite direction for these parameters $(-\mathrm{CCI},+\mathrm{dP} /$ dtmax, and + SVRI). When the change of the transducer's position was $5 \mathrm{~cm}$, the changes of SVRI with error reached statistical significance $(P<0.0001)$, but there were no differences in the CCI between the $5 \mathrm{~cm}$ and $0 \mathrm{~cm}$ reference level $(\mathrm{CCI}:+5 \mathrm{~cm}$ versus $0 \mathrm{~cm} 3.2 \pm 0.6$ versus $3.2 \pm 0.7, P=0.715 ;-5 \mathrm{~cm}$ versus $0 \mathrm{~cm} 3.1 \pm 0.7$ versus $3.2 \pm 0.7, P=0.075)$. When the variation of transducer level was $10 \mathrm{~cm}$, the change of CCI with error reached statistical significance $(P<0.0001)$ (Figure 1$)$. Different positions of the transducer and the corresponding changes in $\mathrm{CCI}$ and $\mathrm{dP} / \mathrm{dtmax}$ are shown in Table 1. Figure 2 shows the trends of estimated marginal means of $\mathrm{CCI}$, CCI change rate, $\mathrm{dP} / \mathrm{dtmax}$, and $\mathrm{dP} / \mathrm{dtmax}$ change rate at different positions of the transducer.

The contour waveform-derived parameter response to the change transducer is still undetermined. To the best of our knowledge, this is the first study to explore the impact of arterial transducer level on pulse contour waveform-derived parameters in clinical practice. The clinical implications of such errors are important to recognize. Our study provided evidence that the arterial transducer should be considered in order to obtain precise pulse contour waveform-derived parameters, especially when the transducer's vertical distance was more than $10 \mathrm{~cm}$ from the phlebostatic axis. We believe that these findings deserve emphasis and should be applied in continuous hemodynamic monitoring.

\footnotetext{
* Correspondence: tjmuhhw@163.com

Department of Critical Care Medicine, Peking Union Medical College

Hospital, Chinese Academy of Medical Science, 1 shuaifuyuan, Dongcheng

District, Beijing 100730, China
} 


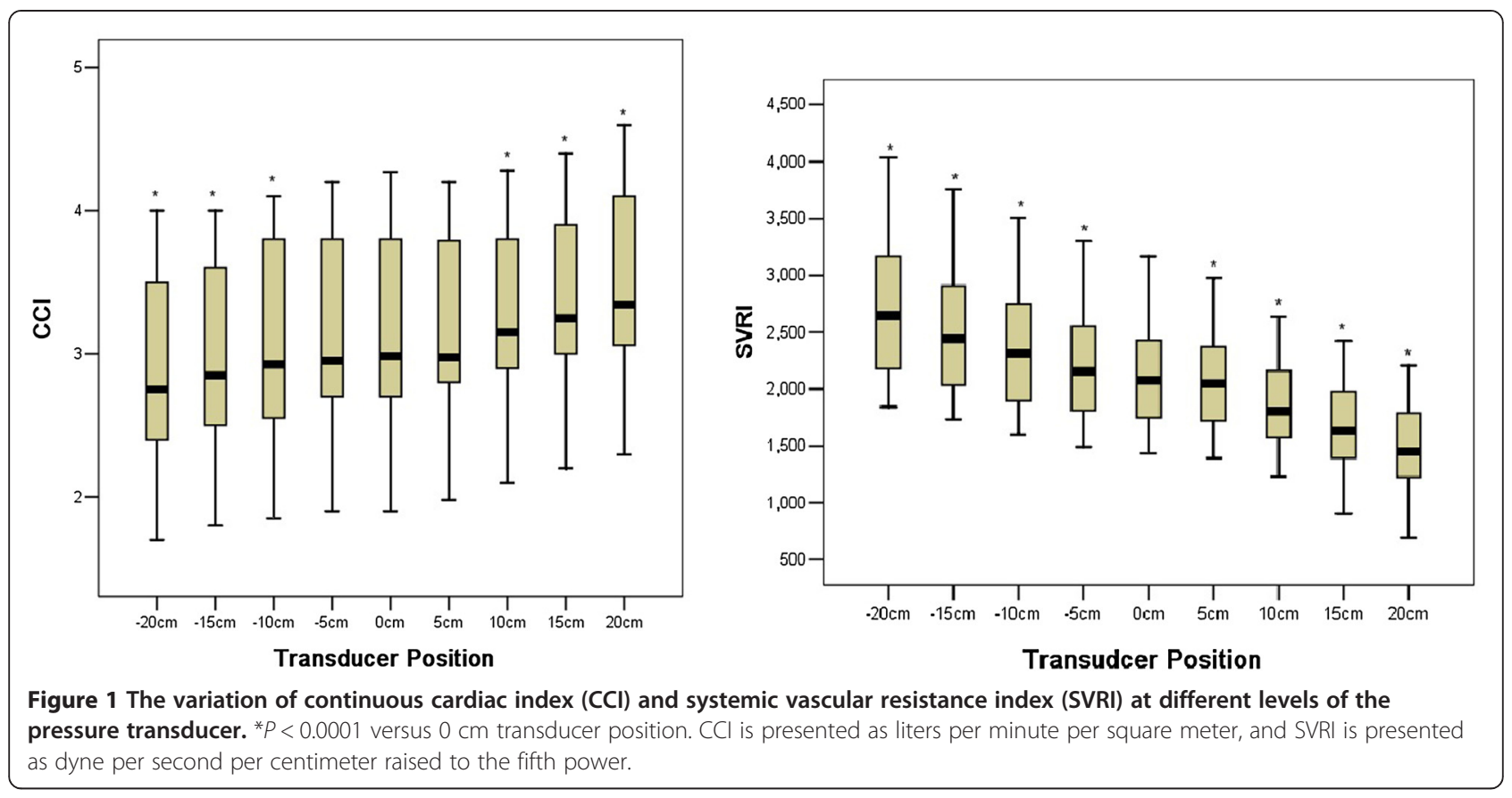

Table 1 Corresponding vertical distances and the changes and variation rates of continuous cardiac index changes and dP/dtmax

\begin{tabular}{lllll}
\hline Vertical distance & $\begin{array}{l}\text { CCl change, } \\
\text { L/minute per } \mathbf{~ m}^{\mathbf{2}}\end{array}$ & $\begin{array}{l}\text { Rate of CCl change, } \\
\text { percentage }\end{array}$ & $\begin{array}{l}\mathbf{d P / d t m a x ~ c h a n g e , ~} \\
\mathbf{m m} \text { Hg/second }\end{array}$ & $\begin{array}{l}\text { Rate of dP/dtmax } \\
\text { change, percentage }\end{array}$ \\
\hline$+20 \mathrm{~cm}$ & 0.36 & 11.9 & -36 & -3.5 \\
$+15 \mathrm{~cm}$ & 0.24 & 7.9 & -27 & -2.6 \\
$+10 \mathrm{~cm}$ & 0.13 & 4.5 & -17 & -1.6 \\
$+5 \mathrm{~cm}$ & 0.01 & 0.31 & -6 & -0.65 \\
$-5 \mathrm{~cm}$ & -0.03 & -0.85 & 9 & 0.9 \\
$-10 \mathrm{~cm}$ & -0.11 & -3.4 & 21 & 2.0 \\
$-15 \mathrm{~cm}$ & -0.20 & -6.4 & 32 & 3.1 \\
$-20 \mathrm{~cm}$ & -0.29 & -9.3 & 44 & 4.1 \\
\hline
\end{tabular}

Data are presented as the mean. $\mathrm{CCl}$, continuous cardiac index; $\mathrm{dP} / \mathrm{dtmax}$, rate of left ventricular pressure rise during systole. 

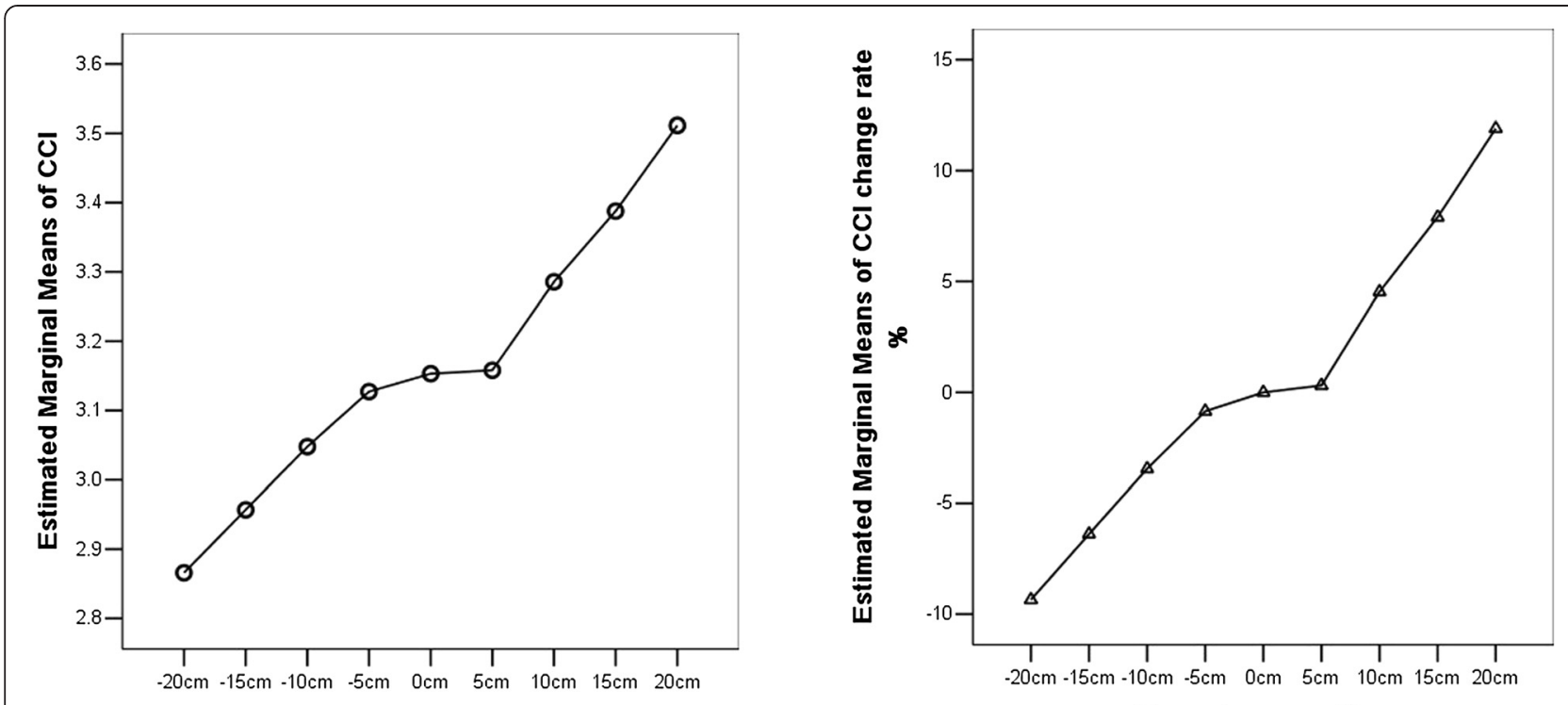

Transducer position
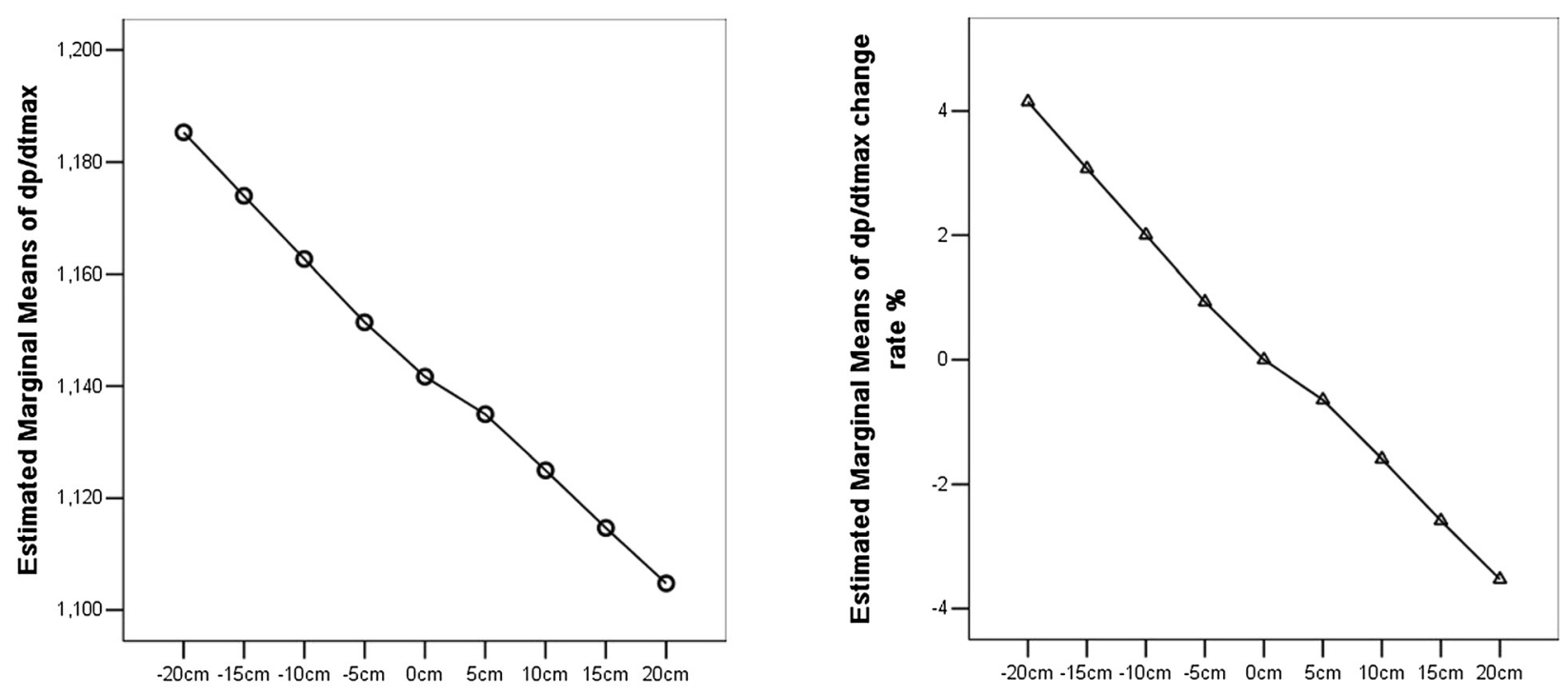

Transducer position

Transducer position

Figure 2 The variation of estimated marginal means of continuous cardiac index $(\mathrm{CCl}), \mathrm{CCl}$ change rate, rate of left ventricular pressure rise during systole (dP/dtmax), and $\mathrm{dP} / \mathrm{dtmax}$ change rate.

\section{Abbreviations}

$\mathrm{CCl}$ : Continuous cardiac index; dP/dtmax: rate of left ventricular pressure rise during systole; SVRI: Systemic vascular resistance index.

\section{Competing interests}

The authors declare that they have no competing interests.

\section{Acknowledgments}

The Institutional Research and Ethics Committee of the Peking Union Medical College Hospital approved this study for human subjects. Written informed consent was obtained from all patients or next of kin before data were included in the study. This work was supported by the special fund for health-scientific research in the public interest program (grant number 201202011, the Ministry of Health of P.R. China). The authors thank for Jing Zhang for reviewing the manuscript for spelling and grammar.

Published online: 02 February 2015

\section{References}

1. Rauen CA, Makic MB, Bridges E. Practice evidence-based practice habits: transforming research into bedside. Crit Care Nurse. 2009;29:46-59.

2. Winsor T, Burch G. Phlebostatic level: reference level for venous pressure measurement in man. Proc Soc Exp Biol Med. 1945;58:165-9.

3. McCann 2nd UG, Schiller HJ, Carney DE, Kilpatrick J, Gatto LA, Paskanik AM. Invasive arterial BP monitoring in trauma and critical care. Chest. 2001;120:1322-6.

4. He HW, Liu DW. Passive leg raising: influence of blood pressure transducer site. Intensive Care Med. 2013;39:1668. 